${ }^{1}$ Departamento de Bioquímica

Clínica e Inmunología, Facultad de Farmacia, Universidad de Concepción.

${ }^{2}$ Instituto de Políticas Públicas en Salud (IPSUSS), Universidad San Sebastián, Concepción. aBioquímico. Candidato a Magíster.

bBioquímica. Magíster en Inmunología.

dMatrona. Doctora en Microbiología.

Recibido el 25 de marzo de 2015, aceptado el 12 de enero de 2016.

Correspondencia a:

Dr. BQ Pedro Alarcón Facultad de Farmacia, Universidad de Concepción.

Barrio Universitario s/número. pedroalarcon@udec.cl

\section{Rol de la microbiota gastrointestinal en la regulación de la respuesta inmune}

\author{
PEDRO ALARCÓN ${ }^{1, a,}$, MARGARITA GONZÁLEZ ${ }^{1, b}$, ÉRICA CASTRO 2,,d,

\section{The role of gut microbiota in the regulation of the immune response}

The gastrointestinal tract hosts around $10^{14}$ bacterial microorganisms, in a constantly growing density from the stomach to the distal colon. This microbiota is composed by more than 500 species of bacteria, which are quickly acquired after birth, fairly stable during the host's life, and essential for human homeostasis. These bacteria have important functions, such as stimulating the immune system, protecting the host from invading bacteria and viruses, and improving digestion, especially of complex carbohydrates. Also, the gut microbiota interacts directly with the immune system. However, the interaction of the intestinal epithelium and its microbiota with the immune system has yet to be fully understood. Secretory immunoglobulin A, produced by the plasma cells in Peyer's patches and in the lamina propria, maintains non-invasive commensal bacteria and neutralize invasive pathogens. Dendritic cells migrate from the lamina propria of the secondary lymphoid organs to regulate gut immunity. They also have a key role maintaining luminal IgA and inducing the growth of regulatory $T$ cells. Dendritic cells supervise the gut microenvironment too, keeping an immunological equilibrium and tolerance. The importance of the gut microbiota in regulating the immune system lies mostly in the homeostasis-or positive equilibrium. Thus, many diseases are a consequence of poor interactions or a loss of this equilibrium.

(Rev Med Chile 2016; 144: 910-916)

Key words: Intestines; Immunity; Microbiota; Probiotics.

\section{L} os humanos vivimos en asociación con un amplio número de microorganismos presentes en la piel, la boca, el sistema genitourinario femenino y el tracto gastrointestinal, conocidos y descritos como microbiota humana normal, un concepto que ha evolucionado desde flora comensal hasta microbioma (Tabla 1). Sin embargo, las mayores concentraciones de organismos comensales se encuentran en el tracto gastrointestinal, el cual tiene un área aproximada de $400 \mathrm{~m}^{2}$ de superficie, constituyendo la segunda superficie más grande en el cuerpo después del tracto respiratorio ${ }^{1}$ y albergando una rica microbiota de $10^{14}$ microorganismos bacterianos, con una densidad de la colonización creciente desde el estómago hasta el colon distal y más de 500 especies bacterianas diferentes; de estas, se ha podido cultivar in vitro sólo 300-500 especies. Como se observa en la Tabla 2, estas bacterias tienen funciones importantes en la salud, tales como estimular el sistema inmune, proteger al huésped ante la invasión de bacterias y virus ${ }^{2}$, y mejorar la digestión, especialmente de carbohidratos complejos ${ }^{3}$.

La microbiota gastrointestinal es adquirida rápidamente después del nacimiento, siendo relativamente estable durante la vida y esencial para la homeostasis humana. En el parto, el recién nacido deja el ambiente intrauterino libre de gérmenes y entra en uno extrauterino altamente contaminado; 
Tabla 1. Evolución de la denominación de las comunidades de microorganismos que habitan en un sitio anatómico

\begin{tabular}{|c|c|c|}
\hline Concepto & Definición & Referencia \\
\hline Flora comensal & $\begin{array}{l}\text { Conjunto de microorganismos que cohabitan, la mayor parte } \\
\text { de los cuales desarrolla relaciones simbióticas de mutualismo } \\
\text { con el huésped y protegen del ingreso de otros potencialmen- } \\
\text { te patógenos }\end{array}$ & $\begin{array}{l}\text { Sarkis K. Mazmanian and Dennis L. } \\
\text { Kasper. Nature Reviews, } 2006\end{array}$ \\
\hline Microbiota & $\begin{array}{l}\text { Comunidades de microorganismos que habitan en forma } \\
\text { estable en un sitio anatómico y que interaccionan entre sí, } \\
\text { autorregulando su concentración numérica y dinámica meta- } \\
\text { bólica, la que puede influir en el estado de salud o enferme- } \\
\text { dad del huésped }\end{array}$ & $\begin{array}{l}\text { Matthew R. Redinbo. J. Mol. Biol., } \\
2014 \\
\text { Jonathan S. Bromberg, y col. Nature } \\
\text { Reviews, } 2015\end{array}$ \\
\hline Microbioma & $\begin{array}{l}\text { Relación entre el huésped y la comunidad microbiana de un } \\
\text { sitio anatómico, donde confluye una compleja interacción de } \\
\text { factores genéticos, ambientales y metabólicos, los que pueden } \\
\text { inducir la expresión o manifestación de una respuesta fisioló- } \\
\text { gica o patológica en el individuo }\end{array}$ & $\begin{array}{l}\text { Jonathan S. Bromberg, y col. Nature } \\
\text { Reviews, } 2015\end{array}$ \\
\hline
\end{tabular}

Tabla 2. Otras funciones de la microbiota

\begin{tabular}{|c|c|c|}
\hline Funciones & Hallazgos & Referencia \\
\hline $\begin{array}{l}\text { Favorece el } \\
\text { metabolismo }\end{array}$ & $\begin{array}{l}\text { Contribución de la microbiota intestinal al metabolismo de los } \\
\text { carbohidratos y las proteínas. Bacteroides thetaiotaomicron es } \\
\text { uno de los principales microorganismos que degradan polisa- } \\
\text { cáridos no digeribles de la dieta. Su genoma contiene } 226 \text { glu- } \\
\text { cósido hidrolasas y } 15 \text { polisacárido liasa. El genoma humano } \\
\text { solo contiene } 98 \text { glucósido hidrolasas y una polisacárido liasa } \\
\text { La microbiota intestinal favorece la transformación metabólica } \\
\text { de los ácidos biliares. Los ácidos biliares actuarían como seña- } \\
\text { lización de moléculas que regulan la absorción de lípidos y la } \\
\text { homeostasis del colesterol }\end{array}$ & $\begin{array}{l}\text { M. Montalto, y col. Digestive and } \\
\text { Liver Disease, } 2009 \\
\text { Mirjana Rajili c-Stojanovi c, } \\
\text { Best Practice \& Research Clinical } \\
\text { Gastroenterology, } 2013\end{array}$ \\
\hline $\begin{array}{l}\text { Prevención de la } \\
\text { aterosclerosis }\end{array}$ & $\begin{array}{l}\text { Existiría una conexión directa entre la microbiota intestinal y } \\
\text { la aterosclerosis. N-óxido - trimetilamina (TMAO) es un com- } \\
\text { puesto orgánico producido por el metabolismo de sustancias } \\
\text { como la colina, fosfatidilcolina, betaína y L-carnitina. Después } \\
\text { que estas sustancias son ingeridas, trimetilamina (TMA) es } \\
\text { producida por la microbiota intestinal. TMA es absorbida en } \\
\text { el torrente sanguíneo y se transfiere al hígado, donde se oxida } \\
\text { en TMAO. Numerosos estudios han encontrado que la colina } \\
\text { se eleva en personas con aterosclerosis }\end{array}$ & $\begin{array}{l}\text { loannis Drosos, y col., Metabolism, } \\
2015\end{array}$ \\
\hline
\end{tabular}

es en las primeras horas después del nacimiento donde tiene lugar el proceso de colonización intestinal. Una gran variedad de factores influye en el proceso de colonización inicial, tales como la edad gestacional, el tipo de parto, la alimentación neonatal y factores genéticos. La microbiota materna constituye una fuente predominante de la colonización inicial. Las primeras bacterias en colonizar el colon neonatal son cepas de Escherichia coli y diversas especies de Enterococcus, junto con anaerobios estrictos. En los bebés alimentados con leche materna, las especies de Bifidobacterium predominan, mientras que los neonatos alimentados con fórmula son colonizados por especies de 
Bacteroides y sólo unos pocos Bifidobacterium $\mathrm{sp}^{4}$. Cuando la microbiota intestinal se está desarrollando, la interacción de ésta con el huésped resulta en la evolución de un sistema inmune intestinal único y distinto. El desafío que enfrenta el sistema inmune de la mucosa del huésped es discriminar entre patógenos y organismos benignos mediante la estimulación protectora de la inmunidad, sin generar una respuesta inflamatoria excesiva que pudiera alterar la integridad de la mucosa gastrointestinal $^{5}$.

El concepto de interacción sinérgica entre el epitelio intestinal y el sistema inmune fue recientemente expandido para incluir la microbiota, la que es ahora considerada como el tercer factor indispensable para una correcta función gastrointestinal ${ }^{6}$. Su capacidad de modular el sistema inmunológico es motivo de investigación, como así también la interacción directa entre estas bacterias y el epitelio gastrointestinal, ya que tendrá un efecto a nivel celular con impacto sistémico. Así, se ha demostrado que distintas bacterias del sistema gastrointestinal con potencial colonizador, in vitro, también son capaces de estimular líneas celulares intestinales, generando un perfil de citoquinas característico ${ }^{7}$.

Está claramente definido que las bacterias de la microbiota intestinal, en su correcta homeostasis, favorecen el estado de salud del humano. Sin embargo, aun con vasta información no está del todo claro el impacto de la interacción de la microbiota gastrointestinal con el sistema inmune y con el propio epitelio en la regulación de la respuesta inmune sistémica.

\section{El epitelio intestinal}

El epitelio intestinal se compone de una sola capa densa de enterocitos a lo largo de las vellosidades de la cripta y se caracteriza por uniones intercelulares estrechas. La arquitectura especial del epitelio intestinal consiste en moléculas altamente específicas sobre la superficie de los enterocitos, las cuales permiten el control y la toma de sustratos para ser absorbidos, manteniendo al mismo tiempo una barrera intacta frente a los impactos antigénicos ${ }^{8}$. La importancia primordial de la función de barrera del epitelio queda en evidencia en el desarrollo espontáneo de colitis en ratones que expresan una mutante dominante de $\mathrm{N}$-cad- herina, asociada con la interrupción de las uniones estrechas entre enterocitos que le confieren esta función ${ }^{9}$. Por lo tanto, un requisito previo para una simbiosis homeostática entre la microbiota intestinal y el huésped es una barrera epitelial intestinal completamente funcional; además, es importante considerar la barrera del epitelio intestinal como un sistema altamente dinámico, y no simplemente como una estructura estática y mecánica. La barrera epitelial es un sistema biológico físico-químico complejo y se compone de un epitelio intestinal apretado, cubierto por una mucosa compuesta de glucoproteínas de mucina, defensinas y otros péptidos antibacterianos o de reparación. También contiene altas concentraciones de IgA secretora ${ }^{4}$.

\section{IgA mantiene la interacción intestinal con la microbiota}

La inmunoglobulina A secretora (S-IgA), producida por las células plasmáticas ubicadas en las placas de Peyer y en la lámina propia, favorece tanto el mantenimiento de las bacterias comensales como la neutralización de patógenos invasores a través de múltiples mecanismos ${ }^{10}$. Uno de estos mecanismos es el bloqueo específico de determinados epítopes bacterianos mediante la unión de S-IgA al antígeno por la región variable, lo que previene la adhesión de bacterias comensales a las superficies apical epitelial y evita el sobrecrecimiento. Adicionalmente, S-IgA limita la movilidad microbiana de bacterias patógenas mediante la unión a flagelina. Además de neutralizar patógenos en el lumen intestinal, S-IgA puede interceptar bacterias intracelulares y toxinas dentro de las células intestinales ${ }^{11}$. Cabe destacar que S-IgA realiza sus funciones de protección sin necesidad de activar el complemento, impidiendo así el daño inflamatorio a la barrera epitelial.

S-IgA forma complejos con bacterias comensales que están en el lumen, y puede volver a la zona subepitelial mediante un receptor especializado en las células con micropliegues (células $\mathrm{M})^{12}$; también presenta selectivamente los componentes bacterianos a células dendríticas con fenotipo $\mathrm{CD} 11 \mathrm{c}^{+} \mathrm{CD} 11 \mathrm{~b}^{+} \mathrm{CD} 8^{-}$, las cuales inducen la producción de interleuquina-10 (IL-10) que contribuye al cambio de clase de la inmunoglobulina a IgA. Este proceso es de vital importancia 
en el establecimiento de un constante monitoreo de S-IgA a especies comensales, asegurando una comunicación efectiva entre la microbiota y el sistema inmune. Esta presentación selectiva de especies comensales induce un ambiente tolerogénico hacia la microbiota.

Por lo tanto, la S-IgA comunica el contenido luminal a la lámina propia mediante el muestreo de bacterias comensales y su presentación a células dendríticas tolerogénicas, que podrían inducir el cambio de clase a IgA mediante un receptor especializado ubicado en células M. Las principales células $\mathrm{T}$ colaboradoras implicadas en la producción de IgA y supervivencia de células $\mathrm{B} \mathrm{IgA}^{+}$en la lámina propia son células $\mathrm{T}$ reguladoras Foxp $3^{+}$.

En resumen, el sistema de IgA es multifacético y actúa para mantener un ambiente antiinflamatorio, compartimentando las respuestas microbianas en el sistema inmune de la mucosa intestinal e induciendo tolerancia hacia la microbiota intestinal normal ${ }^{13}$.

\section{Funciones efectoras de células $\mathrm{B} \operatorname{IgA} \mathrm{A}^{+}$}

Otra función atribuible a los anticuerpos de clase IgA producidos por las células B fue dilucidada por el hallazgo de un subconjunto de células plasmáticas $\operatorname{IgA}^{+}$en la lámina propia. Estas células expresan la óxido nítrico sintasa inducible (iNOS, un factor anti-microbiano) y el factor de necrosis tumoral- $\alpha$ (TNF- $\alpha$ ). Curiosamente, la producción de iNOS por parte de este subconjunto de células $\mathrm{B} \mathrm{IgA}^{+}$es dependiente de la colonización microbiana. Los ratones que crecen en un ambiente libre de gérmenes presentan una completa deficiencia de este subgrupo celular; al ser colonizados con un número limitado de microbiota, la expresión de iNOS en las células plasmáticas $\operatorname{IgA}^{+}$es restau$\mathrm{rada}^{14}$. Además, los ratones deficientes en células plasmáticas IgA ${ }^{+}$iNOS $^{+} \mathrm{TNF}-\alpha^{+}$tienen una producción disminuida de IgA, siendo incapaces de mantener una respuesta inmune clara frente a la infección por Citrobacter rodentium. Estos datos establecen una nueva función efectora de las células plasmáticas $\operatorname{IgA}^{+}$en la producción de factores antimicrobianos in vivo, ampliando aún más el rol de las células $\mathrm{B} \mathrm{IgA}^{+}$en el mantenimiento de la homeostasis intestinal y la respuesta específica de la microbiota, mediante la limitación de la absorción de antígenos ${ }^{15}$.

\section{Células dendríticas y su interacción con la microbiota}

Las células dendríticas migran desde la lámina propia de los órganos linfoides secundarios para regular la inmunidad intestinal; también tienen un papel clave en el mantenimiento de IgA luminal y en la inducción del desarrollo de las células T reguladoras $^{16}$. Además, las células dendríticas muestrean constantemente el microambiente intestinal para mantener el equilibrio y la tolerancia inmunológica a antígenos inocuos durante la respuesta inmune frente a patógenos. Dependiendo de cuáles sean los componentes de la cepa bacteriana, las células dendríticas serán estimuladas, conduciendo a una respuesta mediada por la secreción de IL-12 y de una respuesta tipo Th1, o por la secreción de IL-10 y una respuesta tipo Th2 $2^{17}$.

Está descrito que las células mieloides derivadas de monocitos expresan el receptor de quimioquina CX3CR1, el cual promueve la formación de dendritas transepiteliales para el muestreo de la microbiota luminal ${ }^{18}$. Una subpoblación de células (CX3CR1p) fue propuesta como no migratoria, porque no migró a los ganglios linfáticos mesentéricos tras la estimulación de TLR7 y es una relativamente pobre presentadora de antígeno en cultivo in vitro, en comparación con las células dendríticas de la lámina propia ${ }^{19}$. Por lo tanto, estas células derivadas de monocitos han sido clasificadas como células dendríticas, y en otros estudios se sugiere que estas células pueden, en algunas circunstancias, migrar a los ganglios linfáticos mesentéricos y promover la inducción de células inmunes e inmunoglobulinas ${ }^{20}$.

Se ha demostrado que células dendríticas derivadas de placas de Peyer y del bazo presentan respuestas distintas frente a la estimulación con un agente mimético microbiano (SAC) y CD40L, liberando IL-10 e IL-12 de manera distinta, única y cuantificada, lo que da cuenta de la especificidad de las células dendríticas al responder a estímulos, expresada en la liberación de citoquinas ${ }^{21}$.

Todo esto demuestra que la composición de la microbiota ayuda a mantener la homeostasis inmunológica ${ }^{22}$. Un quiebre en esta alianza homeostática genera la posterior patología, que incluso puede llevar al desarrollo de células con carácter tumoral ${ }^{23}$; por esto, se ha postulado que la microbiota podría ser un órgano más del organismo humano ${ }^{24}$. 
El sistema inmune intestinal ha utilizado diversas estrategias para responder al entorno microbiano de una manera que beneficie a la salud del huésped. Estas estrategias son varias, multifuncionales e interconectadas, y funcionan de una manera específica para evitar el daño epitelial causado por el sistema inmune alterado ${ }^{25}$. Por lo tanto, debe existir un equilibrio armónico entre la microbiota y el epitelio, evidenciado en la homeostasis y un estado de salud beneficioso en el huésped.

Los efectos y mecanismos deducidos de la interacción entre la microbiota, el epitelio y el sistema inmunológico han sido descubiertos en la investigación in vitro,en modelos animales y en estudios a nivel de poblaciones. A pesar de la vasta información y las investigaciones realizadas, no queda del todo claro cómo la microbiota es capaz de participar en este ambiente que interactúa ampliamente con el exterior del organismo humano, dado que, por medio de la dieta, ingresan diversos antígenos dietarios, patógenos, e incluso productos bacterianos como toxinas y medicamentos, que podrían afectar al epitelio. Lo que está claro es que la microbiota intestinal participa en mantener la homeostasis y el estado de salud del huésped ${ }^{26}$.

Sí se puede establecer un cuadro general, comenzando con la S-IgA, la cual participa manteniendo a la microbiota intestinal en cantidades adecuadas para generar la respuesta tolerógenica o antigénica, y colaborando en la presentación antigénica. Esto aún está en discusión, pues se ha descrito que pueden volver mediante receptores especializados ubicados en la célula $\mathrm{M}^{13}$.

También se ha comprobado que la interacción de las células dendríticas con el medio puede desviar la respuesta inmunológica a Th1, Th2 o Treg, las cuales son respuestas únicas, muy especializadas y diferenciadas entre ellas. Eso demuestra cuán complejo y especializado es este sistema, capaz de discriminar entre una respuesta antigénica o tolerógenica ${ }^{21}$.

Finalmente, se han descrito múltiples mecanismos de interacción beneficiosa entre la microbiota y el estado de salud del huésped. Esto demuestra cuán esencial es la microbiota y que el organismo humano no sólo es controlado por células de tipo eucarionte, sino que requiere también la interacción de bacterias (procariontes) para la sobrevivencia y estado de salud, todo esto dentro de un cuadro armónico de cantidades adecuadas de estas bacterias, lo que se debe considerar al momento del consumo de potenciales colonizadores como los probióticos.

Las últimas investigaciones sugieren que la microbiota intestinal puede ser regulada con microorganismos beneficiosos, los que pueden establecer un equilibrio microbiano y prevenir enfermedades al reemplazar a los microorganismos patógenos. Por esto, los probióticos (según la Organización de las Naciones Unidas para la Alimentación y la Agricultura [FAO] y la Organización Mundial de la Salud) son "microorganismos vivos que, administrados en forma adecuada, confieren beneficios al huésped, que van más allá del efecto nutricional primario", y serían unos de los primeros microorganismos que podrían contribuir al balance de la microbiota intestinal ${ }^{26}$.

Se ha demostrado que los microorganismos presentes en el sistema gastrointestinal de personas sanas difieren de los de aquellas personas que presentan alguna enfermedad; estos microorganismos beneficiosos encontrados en el tracto gastrointestinal fueron denominados probióti$\cos ^{27}$, los que tienen características similares a las bacterias comensales que existen en el organismo humano, ya que participan en diversas funciones, como defender o modular el sistema inmune $y$ producir tolerancia al entrar en contacto con diversos antígenos inhalados y alimentarios. Los probióticos también participan en la resistencia a la colonización de bacterias patógenas, ya que al competir con ciertas moléculas en la adhesión impiden la unión de las bacterias patógenas, y expresan y liberan moléculas conocidas como bacteriocinas ${ }^{28}$; además, se ha demostrado que las bacterias probióticas son capaces de responder, in vitro, contra bacterias patógenas ${ }^{29}$.

\section{Mecanismos de acción de los probióticos}

Los mecanismos moleculares exactos de cómo las cepas probióticas participan en la prevención y el tratamiento de enfermedades crónicas del intestino son aún desconocidos; sin embargo, la investigación tanto in vitro, como en modelos animales, apunta a efectos sobre las células epiteliales intestinales y el sistema inmune de mucosas. Recientes estudios in vitro e in vivo demuestran que Lactobacillus y Bifidobacterium ejercen efectos directos sobre la función de barrera del epitelio 
intestinal, evidenciado por la disminución de la permeabilidad intestinal y una mayor resistencia intestinal epitelial. La exposición de células epiteliales de colon T84 a una combinación de Lactobacillus acidophilus y Streptococcus thermophilus induce un aumento en la fosforilación de la actina y las ocludinas, contribuyendo a la formación de uniones estrechas ${ }^{30}$. Se ha demostrado que los probióticos intervienen en los efectos deletéreos de TNF- $\alpha$ e INF- $\gamma$ en la permeabilidad epitelial y el transporte de iones ${ }^{31}$. Además, la suplementación con Bifidobacterium sp. ha generado mayor producción de anticuerpos clase IgA y cambios en la inmunidad mediada por células, incluyendo la presentación de antígenos ${ }^{32}$. También se ha demostrado que Lactobacillus casei DN-114 001 atenúa la respuesta proinflamatoria epitelial intestinal producida por Shigella flexneri patógena ${ }^{33}$.

Está comprobado que los probióticos son capaces de reducir la respuesta inmune inflamatoria -induciendo la apoptosis de células T inflamatorias- y de suprimir la expansión clonal de células T; además, diversas investigaciones están intentando determinar si cepas de probióticos son capaces de alterar la función de las células dendríticas presentadoras de antígeno. Las células dendríticas tratadas con cepas probióticas, en un modelo de colitis experimental con ácido trinitrobenceno sulfónico, confieren protección contra el desarrollo de la colitis, y los análisis moleculares indican que los probióticos fueron capaces de inducir células T reguladoras en este modelo ${ }^{34}$. Otro mecanismo teórico se basa en la supresión, inducida por probióticos, del crecimiento de patógenos a través de la secreción de factores antimicrobianos, tales como el ácido láctico y bacteriocinas. También es posible que algunas cepas probióticas puedan inhibir la interacción de los agentes patógenos con células epiteliales intestinales, demostrado recientemente con Lactobacillus casei DN-114 001, en un experimento que logró reducir la adherencia e invasión de una cepa de Escherichia coli enteroinvasiva aislada de pacientes con enfermedad de Crohn ${ }^{35}$.

Se ha demostrado que existen diversos mecanismos por los que pueden actuar los probióticos, tales como interacción contra productos microbianos, efecto directo sobre otros microorganismos microbianos, e interacción con el sistema inmunológico ${ }^{36}$.

En conclusión, en la regulación de la respuesta inmune, el efecto de la interacción de la microbiota gastrointestinal con el sistema inmune asociado al intestino no radica sólo en un impacto directo a nivel sistémico, sino también en un impacto indirecto, basado en el correcto equilibrio de un sistema de mucosas ampliamente expuesto al exterior $\mathrm{y}$ con funciones determinantes para el correcto funcionamiento metabólico e inmunológico.

Agradecimientos: Al programa de Magíster de Bioquímica Clínica e Inmunología, Departamento de Bioquímica Clínica e inmunología, Facultad de Farmacia, Universidad de Concepción.

\section{Referencias}

1. Bäckhed F, Ding H, Wang T, Hooper LV, Koh GY, Nagy $\mathrm{A}$, et al. The gut microbiota as an environmental factor that regulates fat storage. Proc Natl Acad Sci U S A 2004; 101: 15718-23.

2. Vanderhoof JA. Food hypersensitivity in children. Curr Opin Clin Nutr Metab Care 1998; 1: 419-22.

3. Borchers AT, Selmi C, Meyers FJ, Keen CL, Gershwin ME. Probiotics and immunity. J Gastroenterol 2009; 44: 26-46.

4. Ruemmele FM, Bier D, Marteau P, Rechkemmer G, Bourdet-Sicard R, Walker WA, et al. Clinical evidence for immunomodulatory effects of probiotic bacteria. J Pediatr Gastroenterol Nutr 2009; 48:126-41.

5. Gupta V, Garg R. Probiotics. Indian J Med Microbiol 2009; 27: 202-9.

6. Bäckhed F, Ley RE, Sonnenburg JL, Peterson DA, Gordon JI. Host-bacterial mutualism in the human intestine. Science 2005; 307: 1915-20.

7. Delcenserie V, Martel D, Lamoureux M, Amiot J, Boutin $\mathrm{Y}$, Roy D. Immunomodulatory effects of probiotics in the intestinal tract. Curr Issues Mol Biol 2008; 10: 37-54.

8. Shen L, Turner JR. Role of epithelial cells in initiation and propagation of intestinal inflammation. Eliminating the static: tight junction dynamics exposed. Am J Physiol Gastrointest Liver Physiol 2006; 290: G577-82.

9. Hermiston ML, Gordon JI. Inflammatory bowel disease and adenomas in mice expressing a dominant negative N-cadherin. Science 1995; 270: 1203-7.

10. Phalipon A, Cardona A, Kraehenbuhl JP, Edelman L, Sansonetti PJ, Corthésy B. Secretory component: a new role in secretory IgA-mediated immune exclusion in vivo. Immunity 2002; 17: 107-15.

11. Strugnell RA, Wijburg OL. The role of secretory antibodies in infection immunity. Nat Rev Microbiol 2010; 8: 656-67. 
12. Mestecky J, McGhee JR. Immunoglobulin A (IgA): molecular and cellular interactions involved in IgA biosynthesis and immune response. Adv Immunol 1987; 40: $153-245$.

13. Gutzeit C, Magri G, Cerutti A. Intestinal IgA production and its role in host-microbe interaction. Immunol Rev 2014; 260: 76-85.

14. Fritz JH, Rojas OL, Simard N, McCarthy DD, Hapfelmeier S, Rubino S, et al. Acquisition of a multifunctional IgA+ plasma cell phenotype in the gut. Nature 2012; 481: 199-203.

15. Alexander KL, Targan SR, Elson CO. Microbiota activation and regulation of innate and adaptive immunity. Immunol Rev 2014; 260: 206-20.

16. Sun CM, Hall JA, Blank RB, Bouladoux N, Oukka M, Mora JR, et al. Small intestine lamina propria dendritic cells promote de novo generation of Foxp3 T reg cells via retinoic acid. J Exp Med 2007; 204: 1775-85.

17. Caricilli AM, Castoldi A, Câmara NO. Intestinal barrier: A gentlemen's agreement between microbiota and immunity. World J Gastrointest Pathophysiol 2014; 5: 18-32.

18. Niess JH, Brand S, Gu X, Landsman L, Jung S, McCormick BA, et al. CX3CR1-mediated dendritic cell access to the intestinal lumen and bacterial clearance. Science 2005; 307: 254-8.

19. Schulz O, Jaensson E, Persson EK, Liu X, Worbs T, Agace WW, et al. Intestinal CD103+, but not CX3CR1+, antigen sampling cells migrate in lymph and serve classical dendritic cell functions. J Exp Med 2009; 206: 3101-14.

20. Diehl GE, Longman RS, Zhang JX, Breart B, Galan C, Cuesta A, et al. Microbiota restricts trafficking of bacteria to mesenteric lymph nodes by CX(3)CR1(hi) cells. Nature 2013; 494: 116-20.

21. Iwasaki A, Kelsall BL. Unique functions of CD11b+, CD8 alpha+, and double-negative Peyer's patch dendritic cells. J Immunol 2001; 166: 4884-90.

22. Kelly DF, Pollard AJ, Moxon ER. Immunological memory: the role of $\mathrm{B}$ cells in long-term protection against invasive bacterial pathogens. JAMA 2005; 294: 3019-23.

23. Elinav E, Henao-Mejia J, Flavell RA. Integrative inflammasome activity in the regulation of intestinal mucosal immune responses. Mucosal Immunol 2013; 6: 4-13.

24. McCracken VJ, Lorenz RG. The gastrointestinal ecosystem: a precarious alliance among epithelium, immunity and microbiota. Cell Microbiol 2001; 3: 1-11.

25. Brown EM, Sadarangani M, Finlay BB. The role of the immune system in governing host-microbe interactions in the intestine. Nat Immunol 2013; 14: 660-7.

26. Bron PA, van Baarlen P, Kleerebezem M. Emerging molecular insights into the interaction between probiotics and the host intestinal mucosa. Nat Rev Microbiol 2012; 10: 66-78.

27. Parvez S, Malik KA, Ah Kang S, Kim HY. Probiotics and their fermented food products are beneficial for health. J Appl Microbiol 2006; 100: 1171-85.

28. Oh S, Kim SH, Worobo RW. Characterization and purification of a bacteriocin produced by a potential probiotic culture, Lactobacillus acidophilus 30SC. J Dairy Sci 2000; 83: 2747-52.

29. Michail S, Abernathy F. Lactobacillus plantarum reduces the in vitro secretory response of intestinal epithelial cells to enteropathogenic Escherichia coli infection. J Pediatr Gastroenterol Nutr 2002; 35: 350-5.

30. Resta-Lenert S, Barrett KE. Live probiotics protect intestinal epithelial cells from the effects of infection with enteroinvasive Escherichia coli (EIEC). Gut 2003; 52: 988-97.

31. Resta-Lenert S, Barrett KE. Probiotics and commensals reverse TNF-alpha- and IFN-gamma-induced dysfunction in human intestinal epithelial cells. Gastroenterology 2006; 130: 731-46.

32. Park JH, Um JI, Lee BJ, Goh JS, Park SY, Kim WS, et al. Encapsulated Bifidobacterium bifidum potentiates intestinal IgA production. Cell Immunol 2002; 219: 227.

33. Tien MT, Girardin SE, Regnault B, Le Bourhis L, Dillies MA, Coppée JY, et al. Anti-inflammatory effect of Lactobacillus casei on Shigella-infected human intestinal epithelial cells. J Immunol 2006; 176: 1228-37.

34. Foligne B, Zoumpopoulou G, Dewulf J, Ben Younes A, Chareyre F, Sirard JC, et al. A key role of dendritic cells in probiotic functionality. PLoS One 2007; 2: e313.

35. Ingrassia I, Leplingard A, Darfeuille-Michaud A. Lactobacillus casei DN-114001 inhibits the ability of adherent-invasive Escherichia coli isolated from Crohn's disease patients to adhere to and to invade intestinal epithelial cells. Appl Environ Microbiol 2005; 71: 28807.

36. Oelschlaeger TA. Mechanisms of probiotic actions-A review. Int J Med Microbiol 2010; 300: 57-62. 